\title{
BMJ Open Primary care integration of sexual and reproductive health services for chlamydia testing across WHO-Europe: a systematic review
}

\author{
Harumi Quezada-Yamamoto, ${ }^{1}$ Elizabeth Dubois, ${ }^{1}$ Nikolaos Mastellos, ${ }^{2}$ \\ Salman Rawaf ${ }^{1}$
}

To cite: Quezada-Yamamoto $\mathrm{H}$, Dubois E, Mastellos N, et al. Primary care integration of sexual and reproductive health services for chlamydia testing across WHO-Europe: a systematic review. BMJ Open 2019;9:e031644. doi:10.1136/ bmjopen-2019-031644

- Prepublication history and additional material for this paper are available online. To view these files, please visit the journal online (http://dx.doi. org/10.1136/bmjopen-2019031644).

Received 14 May 2019 Revised 10 September 2019 Accepted 17 September 2019

Check for updates

(c) Author(s) (or their employer(s)) 2019. Re-use permitted under CC BY-NC. No commercial re-use. See rights and permissions. Published by BMJ.

${ }^{1}$ WHO Collaborating Centre, Department of Primary Care and Public Health, Imperial College London, London, UK ${ }^{2}$ Department of Primary Care and Public Health, Imperial College London, London, UK

Correspondence to Dr Harumi Quezada-Yamamoto; harumi.quezada-yamamoto17@ imperial.ac.uk

\section{ABSTRACT}

Objective To identify current uptake of chlamydia testing (UCT) as a sexual and reproductive health service (SRHS) integrated in primary care settings of the WHO European region, with the aim to shape policy and quality of care. Design Systematic review for studies published from January 2001 to May 2018 in any European language. Data sources OVID Medline, EMBASE, Maternal and Infant Care and Global Health.

Eligibility criteria Published studies, which involved women or men, adolescents or adults, reporting a UCT indicator in a primary care within a WHO European region country. Study designs considered were: randomised control trials (RCTs), quasi-experimental, observational (eg cohort, case-control, cross-sectional) and mixed-methods studies as well as case reports.

Data extraction and synthesis Two independent reviewers screened the sources and validated the selection process. The BRIGGS Critical Appraisal Checklist for Analytical Cross-Sectional Studies, the Mixed Methods Appraisal Tool 2011 and Critical Appraisal Skills Programme (CASP) checklists were considered for quality and risk of bias assessment.

Results 24 studies were finally included, of which 15 were cross-sectional, 4 cohort, 2 RCTs, 2 case-control studies and 1 mixed-methods study. A majority of the evidence cites the UK model, followed by the Netherlands, Denmark, Norway and Belgium only. Acceptability if offered test in primary healthcare (PHC) ranged from 55\% to $81.4 \%$ in women and from $9.5 \%$ to $70.6 \%$ when both genders were reported together. Men may have a lower UCT compared with women. When both genders were reported together, the lowest acceptability was $9.5 \%$ in the Netherlands. Denmark presented the highest percentage of eligible people who tested in a PHC setting (87.3\%). Conclusions Different health systems may influence UCT in PHC. The regional use of a common testing rate indicator is suggested to homogenise reporting. There is very little evidence on integration of SRHS such as chlamydia testing in PHC and there are gaps between European countries.

\section{INTRODUCTION}

\section{Rationale}

In 1978, the Alma-Ata Declaration positioned primary healthcare (PHC) as 'the key
Strengths and limitations of this study

- This literature review, unlike previous attempts, is exclusive to the European region.

- The search was exhaustive as it included the 53 countries belonging to WHO European region and all European languages.

- 48 of 53 countries may not show data due to a diversity of research and health system particularities of the states.

- Grey literature was not considered.

to the attainment of the goal of 'Health for All". ${ }^{1}$ Sixteen years later, the 1994 International Conference on Population and Development encouraged the provision of sexual and reproductive health services (SRHS) in an integrated way within the primary care health system. ${ }^{2}$ By the early $2000 \mathrm{~s}$, the WHO further recommended integrating other health services, like SRHS with primary care. ${ }^{3}$ At the 60th UN General Assembly in 2005 a message was sent that in order to achieve universal access to reproductive health by 2015, SRHS were to be delivered through PHC. ${ }^{1}$ Five years later, a meeting held in Ankara reinforced this message to the European countries. ${ }^{4}$ Most recently in 2018, the Astana Declaration emphasised the critical role of PHC around the world, to ensure that everyone is able to enjoy the highest possible attainable standard of health. Today, PHC needs to increase its responsive capacity and to standardise such integrated delivery of SRHS. ${ }^{2}$ Currently, the UN Sustainable Development Goals \#3 (good health/well-being) and \#5 (gender equality) require that safe and essential SRHS are accessible to all. Evidence on how this has been achieved in the European region (understood as the 53 countries integrating the WHO European region) is 
limited, particularly regarding chlamydia testing. With the exception of the UK, very few European countries have taken action.

Ideally, according to the WHO, SRHS programmes must serve all segments of the population and yet contain different components to serve five specialty areas: (1) maternal and new-born health; (2) family planning; (3) prevention of unsafe abortion; (4) management of reproductive tract infections and sexually transmitted infections (STIs), including HIV/AIDS and (5) promotion of sexual health. ${ }^{2}$ This research focusses on the fourth area, STIs, specifically chlamydia infection testing. Chlamydia is the most commonly STI in Europe, with most of the cases being asymptomatic but leading to complications such as pelvic inflammatory disease and infertility. ${ }^{5}$

The integration of chlamydia testing can be at three different levels: at the point of service delivery (POSD), at the health sector level and within national development planning processes. ${ }^{2}$ In this sense, the present analysis will concentrate on exploring the integration at the POSD (uptake).

Previous systematic reviews focussed on low-income and middle-income countries (mostly in Africa) and did not analyse Europe as a region or did not emphasise the primary care settings. In 2013, Jamil et al reviewed chlamydia testing strategies and outcomes but only in homebased programmes in the United States/Canada, Europe, Australia/New Zealand and Asia from 2005 to 2011. ${ }^{5}$ In 2015, Crichton et al published a systematic review on chlamydia prevalence derived from population-based samples from testing that included young people aged 15-24years from Europe, North America or Australia. ${ }^{6}$ The Crichton's review focussed on providing evidence of a consistent association between socioeconomic disadvantages and the higher risk of chlamydia infection. ${ }^{6}$ The same year Phillipson et al appraised the effectiveness of chlamydia testing interventions from 2002 and 2012 in Australia and Europe (including the UK), targeting young adults in community-based settings, describing the strategies used and assessing them according to social marketing benchmark criteria. ${ }^{7}$ Today, our systematic review will add a regional panorama, focused on primary care settings point of service delivery uptake of this particular intervention and with the aim to shape policy and quality of care.

For the purpose of our research, we define primary care as a component of PHC, referring to the first level of contact people have with healthcare teams. ${ }^{1}$ In the current study, primary care venues considered were: general practitioner (GP), family medicine or general medicine clinics. We recognise that SRHS are integrated', when the practices provide specialised services such as chlamydia testing within the PHC setting and that HIV screening, abortion procedures and contraceptive methods are also part of the SRHS but will not be the focus of the research. Nevertheless, they could be indicators of integration.

\section{Objectives}

To identify the current uptake of chlamydia testing (UCT) as an SRHS integrated in primary care settings of the WHO European region. Findings will shape further policy, detect gaps in research and identify variation in practice between countries.

\section{Research question}

The academic query that guided this research was:

What is the uptake of chlamydia testing among adolescent and adult population, in primary care settings across the WHO European region?

\section{METHODS}

\section{Literature search}

The study design is a systematic review of the literature. A two-step search strategy was used:

1. Initial search through MEDLINE followed by analysis of the text words contained in the title and abstract and of the index terms used to describe an article.

2. Search using all identified keywords and index terms was then undertaken across the included electronic databases (OVID Medline, EMBASE, Maternal and Infant Care, Global Health).

A list of search terms can be found in online supplementary appendix A.

\section{Inclusion criteria}

To ensure a systematic and structured analysis, we adopted the PICOS framework that is used to answer clinical or health related questions. The P stands for patient, problem or population; I: intervention; C: comparison; O: outcome and S: study design. Using 'population' for P, the PICOS criteria for this research are as follows:

P: Female and male, adolescent or adult patients (more than or equal to 12 years old) from countries within the WHO European region.

I: Chlamydia testing in primary care settings (GP or family medicine practices).

C: Differences in uptake and model between countries.

O: PHC POSD uptake (see indicators below).

S: Cohort, case-controls, cross-sectional studies or case reports.

The study outcome indicators on the UCT were:

- The percentage of acceptability if offered testing in PHC (eg, if the GP invites a patient to undertake a chlamydia test and they attend).

- The percentage of patients tested in PHC (coverage) (eg, of the population studied, the percentage of those tested in PHC instead of other venues, for example, a sexual health clinic);

- The percentage of high-risk patients getting tested in PHC (eg, high-risk individuals, for example, sex workers, tested in a PHC venue recognised in this study). 
- The percentage of "x" gender tests (men or women or both) performed in PHC, (eg, of all tests done for women in the population studied, the proportion of those made in PHC).

- The percentage of tests in PHC that were performed on "x" gender (men or women or both), (eg, of all tests done in PHC in a Danish province, the proportion of tests performed in men).

- The percentage of PHC patients requesting chlamydia testing when consulted for STI (eg, of all the patients in a PHC clinic that consult for an STI, the percentage who ask for chlamydia testing).

- The percentage of patients in PHC who get tested (eg, of all the patients in a $\mathrm{PHC}$ clinic, the percentage who received chlamydia testing).

\section{Data extraction}

The selected studies were stored and processed on ENDNOTE7. Quantitative data were extracted in a Microsoft Word table, including: country (setting), year, author, study type, uptake (men, women and both), positivity/ prevalence and age. Author email contact was considered if any data confirmation was required from investigators.

\section{Quality assessment}

Two independent reviewers screened the sources and validated the selection process. The Joanna Briggs Institute's Critical Appraisal Checklist for Analytical Cross-Sectional Studies (BRIGGS), the Mixed Methods Appraisal Tool (MMAT) 2011 and Critical Appraisal Skills Programme (CASP) checklists were considered for quality and risk of bias appraisal (see table 1).

\section{Patient and public involvement}

No patient involved.

\section{RESULTS}

The flow diagram of the studies retrieved for the review is shown in figure 1. In total, 24 studies were finally included in the analysis, of which 15 were cross-sectional studies, 4 cohort studies, 2 randomised control trials (RCTs), 2 case-control studies and 1 mixed-methods study. Table 1 shows the individual tool assessment results for each of the included studies. No serious risk of bias or quality was detected. Of the 53 countries of the WHO European region and that were included in the search strategy, only 5 showed results. The majority of studies originated from the UK (14) followed by the Netherlands (4) Denmark (3) Norway $(2)^{2}$ and Belgium (1). The population reported has a minimum age of 12 years and a maximum age of 70 years. In most studies, those tested ranged between 16 and 25 years old.

RCT interventions included two different population screening strategies: The UK general practice ${ }^{8}$ and a register-based, yearly chlamydia screening in three regions of the Netherlands: Amsterdam, Rotterdam and South Limburg. ${ }^{9}$ In general, the studies' objectives

\begin{tabular}{|c|c|c|c|}
\hline Year & Author & Study type & Score \\
\hline 2001 & Johansen et $a l^{12}$ & Cross-sectional & 5/8 (BRIGGS) \\
\hline 2003 & Kufeji et $a l^{20}$ & Cross-sectional & 6/8 (BRIGGS) \\
\hline 2003 & Pimenta et $a l^{21}$ & Mixed methods & 12/13 (MMAT) \\
\hline 2004 & Strand et $a l^{22}$ & Cohort & $\begin{array}{l}10.5 / 12 \\
\text { (CASP) }\end{array}$ \\
\hline 2004 & Verhoeven et $a l^{10}$ & Cross-sectional & 6/8 (BRIGGS) \\
\hline 2005 & McCadden et $\mathrm{a}^{23}$ & Cross-sectional & 6/8 (BRIGGS) \\
\hline 2005 & Andersen et $\mathrm{a}^{24}$ & $\mathrm{Ca}$ & $\begin{array}{l}10.5 / 11 \\
\text { (CASP) }\end{array}$ \\
\hline 2005 & Harris $^{25}$ & Cohort & 10/12 (CASP) \\
\hline 2005 & Senok et $a l^{8}$ & $\mathrm{RCT}$ & 11/11 (CASP) \\
\hline 2007 & Hughes et $a l^{26}$ & Cross-sectional & 6/8 (BRIGGS) \\
\hline 2008 & Neale et $a l^{27}$ & Cross-sectional & 6/8 (BRIGGS) \\
\hline 2008 & Sohal et $a^{28}$ & Cross-sectional & 5/8 (BRIGGS) \\
\hline 2009 & Creighton ${ }^{29}$ & Cross-sectional & 5/8 (BRIGGS) \\
\hline 2010 & Sadler et $\left.a\right|^{30}$ & Cross-sectional & 7/8 (BRIGGS) \\
\hline 2012 & Woodhall et $\left.a\right|^{31}$ & Cross-sectional & 6/8 (BRIGGS) \\
\hline 2012 & Van den Broek et al ${ }^{9}$ & $\mathrm{RCT}$ & 11/11 (CASP) \\
\hline 2012 & Saunders et $a^{32}$ & Cross-sectional & 8/8 (BRIGGS) \\
\hline 2013 & Trienekens et $a l^{33}$ & Cohort & $\begin{array}{l}10.5 / 12 \\
\text { (CASP) }\end{array}$ \\
\hline 2014 & Van Liere et $a l^{34}$ & Cross-sectional & 8/8 (BRIGGS) \\
\hline 2014 & Kelly $^{35}$ & Cohort & 10/12 (CASP) \\
\hline 2014 & Pedersen ${ }^{36}$ & Case-control & 11/11 (CASP) \\
\hline 2015 & Buijs $^{37}$ & Cross-sectional & 5/8 (BRIGGS) \\
\hline 2016 & Clifton et $\left.a\right|^{38}$ & Cross-sectional & 7/8 (BRIGGS) \\
\hline 2017 & Romoren ${ }^{39}$ & Cross-sectional & 6/8 (BRIGGS) \\
\hline
\end{tabular}

CASP, Critical Appraisal Skills Programme ; MMAT, Mixed Methods Appraisal Tool; RCT, randomised control trial.

inclined towards effectiveness evaluations. Under the 'effectiveness' tag, uptake indicators were measured. The geographical location of the studies can be consulted in table 2.

Uptake data were defined through different indicators as seen in table 3. Acceptability stands for the percentage of people who take the test after it has been offered. The ranges on the table outline the minimum and maximum values reported in the countries analysed, giving a regional value. Values that were reported by only one country have it specified in parenthesis.

The results (table 3 ) indicate that men may have a lower uptake rate than women. The highest acceptability in women was $81.4 \%$ against $29.4 \%$ in men. When genders were combined, the lowest acceptability rate reported was $9.5 \%$ in the Netherlands. The percentage of women who got tested in PHC varies from 27\% to 50\%, contrasting the range of $6 \%-17.1 \%$ among men. Denmark presented the highest percentage of people who got tested in a PHC setting $(87.3 \%)$. Positivity of tests performed in a primary 

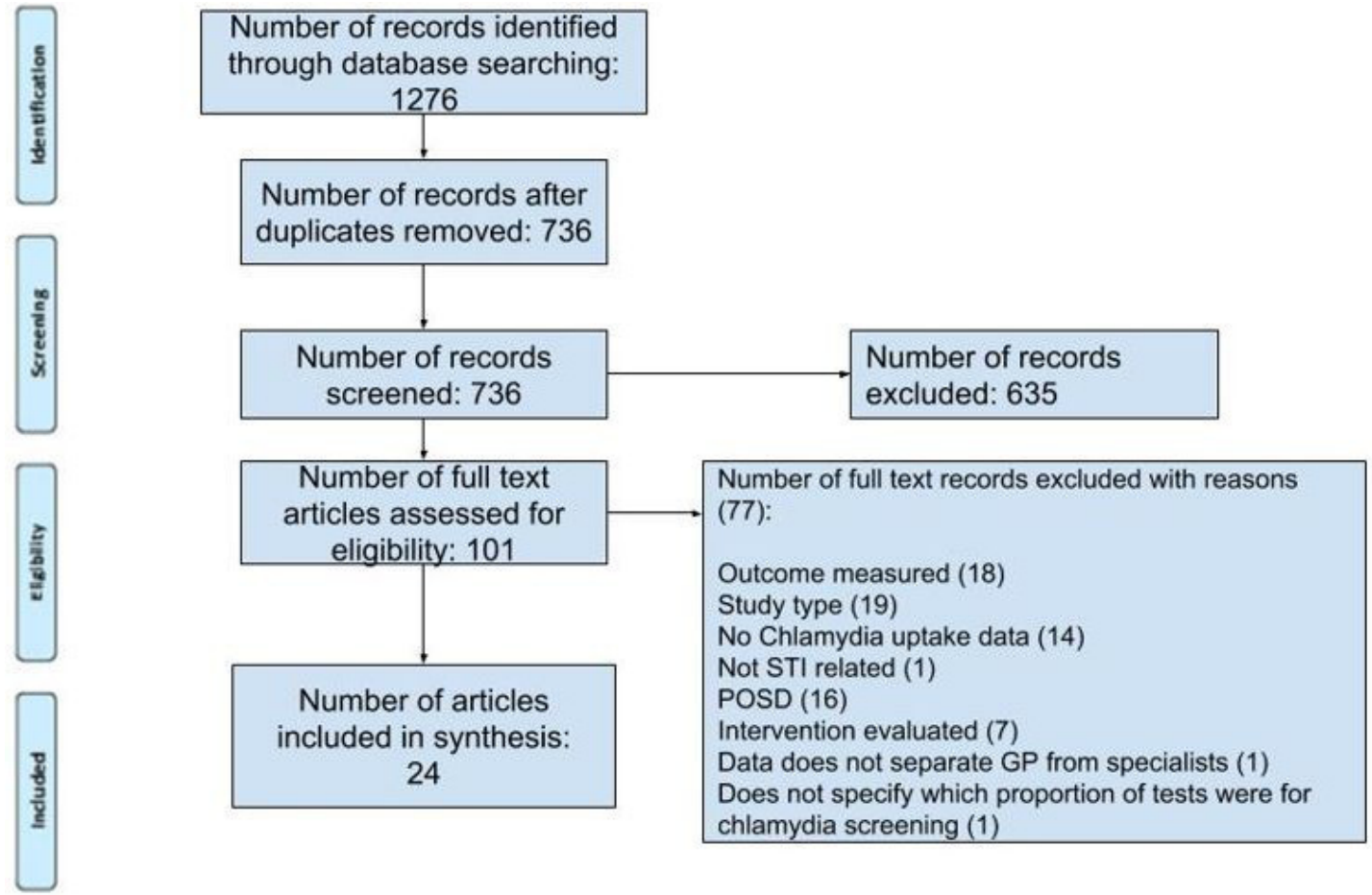

Figure 1 Prisma flow chart.

Exclusion reasons: 'Outcome measured' involves those papers that did not include any of the outcome measures as stated on the PICOS, while 'No Chlamydia uptake data' contains those which measured STI testing but did not disaggregate the results for chlamydia. 'Intervention evaluated' comprises papers which intervention was not related to the aim of this paper. POSD, point of service delivery.

care setting ranged from $1.5 \%$ to $20.8 \%$ among women, from $2.2 \%$ to $30 \%$ among men and from $4.3 \%$ to $14.7 \%$ when both genders were reported together.

\begin{tabular}{|c|c|}
\hline Country & Locations \\
\hline UK & $\begin{array}{l}\text { Britain (National) }{ }^{23263238} \\
\text { England (National) }^{31} \\
\text { Nottingham }^{20} \\
\text { Wirral and Portsmouth/South East } \\
\text { Hampshire } \\
\text { Sheffield }^{25} \\
\text { Scotland }^{8} \\
\text { Cornwall } \\
\text { London }^{28} 29 \\
\text { Brent and Avon }^{30} \\
\text { Northern Ireland }^{35}\end{array}$ \\
\hline Netherlands & $\begin{array}{l}\text { National }^{33} \\
\text { Amsterdam, Rotterdam and South } \text { Limburg }^{9} \\
\text { South Limburg } \\
\text { Amsterdam and Gooi }\end{array}$ \\
\hline Denmark & $\begin{array}{l}\text { Frederiksborg County }{ }^{12} \\
\text { Ringkjøbing County }{ }^{24} \\
\text { Copenhagen }^{36}\end{array}$ \\
\hline Norway & $\begin{array}{l}\text { Trondheim } \\
\text { Vestfold }^{22}\end{array}$ \\
\hline Belgium & Antwerp ${ }^{10}$ \\
\hline
\end{tabular}

The research from Verhoeven and colleagues was the only one to provide data from Belgium in the form of an 'effective screening rate in women at risk', meaning women eligible for testing, consented, with a urine sample provided and a valid result obtained. ${ }^{10}$ The 'overall effective screening rate' was also used. This stands for tests performed with a valid result in women at risk and no test in women not at risk. ${ }^{10}$

\section{DISCUSSION}

\section{Main findings}

The database search generated 24 studies to be included in the review. Only 5 of the 53 countries comprising the systematic review generated results (9\% of the region). These countries being the UK, Netherlands, Denmark, Norway and Belgium. More than 60\% (15 of 24) of the selected studies were cross-sectional. At the same time, there was clear predominance of UK research. This study showed data heterogeneity and lack of unified reporting indicators for chlamydia testing uptake in primary care, across the European region.

In the UK, healthcare provision is mainly through the National Health Service (NHS). Strong initiatives such as the National Chlamydia Screening Programme (NCSP), established in 2003, have set the topic under scope, and therefore, encouraged research in the area. Public Health England recommends a local detection rate of at least 2300 per 100000 population. 'Local authorities have 
Table 3 Summary of UCT reported in $\mathrm{PHC}^{8-10} 12$ 20-39

\begin{tabular}{|c|c|c|c|}
\hline Indicator & Women & Men & Both genders \\
\hline Acceptability if offered test in PHC & $55 \%-81.4 \%$ & $3.8 \%-29.4 \%$ (Denmark) & $9.5 \%-70.6 \%$ \\
\hline \% who got tested in PHC (coverage) & $27 \%-50 \%$ & $6 \%-17.1 \%$ & $3.32 \%-87.3 \%$ \\
\hline$\%$ of " $x$ " gender tests performed in $\mathrm{PHC}$ & $18 \%(U K)$ & $5.1 \%-9 \%(\mathrm{UK})$ & $15 \%-21 \%$ \\
\hline$\%$ of the tests in PHC that were performed on " $\mathrm{x}$ " gender & $63.1 \%-98 \%$ & $2 \%-36.9 \%$ (calculated) & \\
\hline$\%$ patients in $\mathrm{PHC}$ who get tested & & & $61.7 \%-63.8 \%(U K)$ \\
\hline
\end{tabular}

PHC, primary healthcare; STI, sexually transmitted infection; UCT, uptake of chlamydia testing.

a statutory duty to ensure the provision of open access services including free STI testing and treatment. The chlamydia screening policy in the UK establishes that testing should be offered as an integrated component of existing SRHS including primary care based services'. ${ }^{11}$

Overall, both acceptance and coverage are higher in women. Similarly, testing opportunities target mostly women. For example, in Denmark, the testing is offered before inserting an intrauterine device or coil (IUD) and most studies analyse women populations. ${ }^{12}$ The Danish Guideline indicates opportunistic chlamydia testing in primary care for asymptomatic individuals with frequent sex partner change, women under 26 before IUD insertion or hysterosalpingogram. Notwithstanding, it is important to reinforce the message to clinical practitioners and researchers, that men are carriers and should be tested as much as women.

Most women and men will accept the test if offered, compared with the GP waiting for the patient to request it. However, the Netherlands presents lower acceptability, possibly due to their insurance health system structure, that does not cover STI testing for people over 25 years old unless they belong to a risk group (eg, sex workers), making it an out-of-pocket expenditure, different from the NHS (UK) in which this test is offered for free, in line with other services. ${ }^{13-15}$ The Dutch General Practitioners' Society (NHG) standards state that young people under 25 years of age regardless of complaints or risk group should always be offered a chlamydia test.

As mentioned, Denmark presented the highest percentage of tested people $(87.3 \%$; both genders reported together) who did so in a PHC setting. We could assume this is due to the strong gatekeeping role of the GPs within their healthcare system. The majority of the Danish population (98\%) is registered with their GPs. ${ }^{15}$ $22 \%$ of physicians work in general practice and their income depends on $30 \%$ of capitation and on $70 \%$ on fee-for-service. ${ }^{16}$

Norwegian studies reported scattered information and more evidence would be needed to identify current uptake. Nonetheless, they appear to follow the trend of higher uptake among women compared with men. Norwegian country guidelines currently recommend testing individuals under 25 years of age, regardless of sex when there is a change of sexual partner, pregnancy or IUD insertion. Other indications include symptomatic patients, women performing abortions, men who have sex with men and persons identified through contact tracing. Norway does not have an opportunistic or systematic screening programme for chlamydia. However, chlamydia testing is available at no extra cost at GP surgeries, in hospitals and specialised clinics.

Belgian doctors do not have a national guideline for STI management. Nevertheless, a general practice guideline named 'early detection of chlamydia trachomatis' has been disseminated in Flanders (northern Belgium) and early detection of STIs was part of a national prenatal care guideline.

The 'overall effective screening rate' used by Verhoeven and colleagues is valuable in the sense that it provides information regarding valid tests only. Valid tests mean those with samples that were actually possible to process by the laboratory and produced results, as sampling, storage and transport conditions may not always meet the standards required. Therefore, it gives a more accurate picture of successful screening. ${ }^{10}$ On that account, this type of indicator could be useful for shaping policy and should be considered for report standardisation of the countries within the region.

In 2009, the WHO's Department of Reproductive Health and Research performed a survey on the role of PHC in SRHS primarily in low-income and middle-income countries. ${ }^{1}$ A similar study should be carried out across the European region in order to get together information on how SRHS are provided in each country by primary care providers. This will help to shape policy by detecting not only the current gaps but also multiplicity of services provision. To improve the testing uptake, triple integration of primary care, SRHS and public health should be considered to eliminate service duplication and deliver effective service. ${ }^{17}$

Our results are slightly similar to those of Uusküla and colleagues in 2014 and 2017, ${ }^{18} 19$ regarding the difficulty of results generalisability and percentage of tests performed in PHC with both genders reported together $\left(15 \%-21 \%\right.$ vs $\left.6 \%-18 \%{ }^{18}\right)$. Nevertheless, comparison is 
not completely possible as the sources and country mix in the studies are different.

The authors believe that, despite the existence of STI or genitourinary medicine (GUM) clinics, the role of the GP in chlamydia testing is unique. Visits to STI/ GUM services still carry, to some extent, an associated stigma while the GP (family doctor) is considered a figure in the community to be trusted and where people's motivation to seek care or advice is under less social scrutiny.

\section{Strengths and limitations}

The key strength of this research stems from the exclusiveness of the findings to one geographical area (Europe) and the exhaustiveness in the sense that all 53 countries belonging to the WHO region were considered in the database search. This contrasts with previous systematic reviews in that they mixed countries from different continents, making it difficult to analyse the region. Such fact makes the findings valuable as a new addition to the literature.

An additional strength of the study is that due to the selected inclusion criteria, it allowed for country comparisons and detection of non-reporting countries. Furthermore, it highlighted the need for standardised primary care electronic databases that allow homogeneous data collection. The category of data generated by this study is highly valued by the WHO and other international organisations.

The term 'integration' has different meaning in different countries (merged service, working together, SRH professional based in primary care and so on). Therefore, generalising the results becomes more difficult. However, it was possible to link PHC through the words commonly used to address it. For example, family doctor, family medicine, GP, community medicine, community nurses and so on. Countries with no study data reported may be due to:

- The study names primary care with an uncommon term not listed in the inclusion criteria.

- The country does not perform chlamydia testing in primary care, but may perform other SRHS like HIV screening.

- The country does not have any SRHS within primary care.

- There is no research on this specific topic in the country.

- The data are only available in the grey literature.

\section{CONCLUSION}

Steps towards the integration of SRHS with primary care, such as chlamydia testing, are sparsely documented and a paucity of evidence is available between the European countries. It seems that women have a greater UCT in primary care settings compared with men. However, further research is needed to produce an accurate view of the region. The UK is the country with most documented evidence, followed by the Netherlands, although acceptance for chlamydia testing in the latter is lower when offered.

Acknowledgements The Department of Primary Care and Public Health at Imperial College London is grateful for support from the NIHR Collaboration for Leadership in Applied Health Research \& Care (CLAHRC) Scheme, the NIHR Biomedical Research Centre scheme and the Imperial Centre for Patient Safety and Service Quality. The WHO Collaborating Centre provided logistic and technical support. We would like to thank the general practices and primary care professionals who agreed to participate and contribute to this research. We would like to thank Imperial College London, especially the Department of Primary Care and Public Health, for the support towards the activities of the WHO Collaborating Centre.

Contributors $\mathrm{HQ}$ initiated and designed the study, analysed the data, drafted the original manuscript, interpreted the results and revised subsequent drafts, $H Q$ and ED assessed quality of the selected studies. ED, NM and SR revised the design and subsequent drafts. All authors discussed data analyses and contributed to interpretation of results. All the authors approved the final manuscript for publication. This article presents independent research supported by the National Institute for Health Research (NIHR) under the Collaboration for Leadership in Applied Health Research and Care (CLAHRC) programme for Northwest London. The views expressed in this publication are those of the authors and not necessarily those of the NHS, the NIHR or the Department of Health and Social Care.

Funding The authors have not declared a specific grant for this research from any funding agency in the public, commercial or not-for-profit sectors.

Competing interests None declared.

Patient consent for publication Not required.

Provenance and peer review Not commissioned; externally peer reviewed.

Data availability statement No data are available.

Open access This is an open access article distributed in accordance with the Creative Commons Attribution Non Commercial (CC BY-NC 4.0) license, which permits others to distribute, remix, adapt, build upon this work non-commercially, and license their derivative works on different terms, provided the original work is properly cited, appropriate credit is given, any changes made indicated, and the use is non-commercial. See: http://creativecommons.org/licenses/by-nc/4.0/.

\section{REFERENCES}

1 World Health Organization. Sexual and reproductive health core competencies in primary care. World Health Organization, 2011.

2. World Health Organization. Integrating sexual and reproductive health-care services. Geneva, Switzerland: WHO, Dept. of Reproductive Health and Research, 2006.

3. World Health Organization. Who Regional Strategy on Sexual and Reproductive Health. Copenhagen, Denmark: WHO Regional Office for Europe, November 2001.

4 Aarendonk D, de Maeseneer J. EFPC: European forum for primary care. Eur J Gen Pract 2011;17:76-7.

5 Jamil MS, Hocking JS, Bauer HM, et al. Home-Based Chlamydia and gonorrhoea screening: a systematic review of strategies and outcomes. BMC Public Health 2013;13:189.

6 Crichton J, Hickman M, Campbell R, et al. Socioeconomic factors and other sources of variation in the prevalence of genital Chlamydia infections: a systematic review and meta-analysis. BMC Public Health 2015;15:729.

7 Phillipson L, Gordon R, Telenta J, et al. A review of current practices to increase Chlamydia screening in the community--a consumercentred social marketing perspective. Health Expect 2016;19:5-25.

8 Senok A, Wilson P, Reid M, et al. Can we evaluate population screening strategies in UK general practice? A pilot randomised controlled trial comparing postal and opportunistic screening for genital chlamydial infection. J Epidemiol Community Health 2005;59:198-204.

9 van den Broek IVF, van Bergen JEAM, Brouwers EEHG, et al. Effectiveness of yearly, register based screening for Chlamydia in the Netherlands: controlled trial with randomised stepped wedge implementation. BMJ 2012;345:e4316.

10 Verhoeven V, Avonts D, Van Royen P, et al. Implementation of a pilot programme for screening for chlamydial infection in general practice. Eur J Gen Pract 2004;10:157-61. 
11 England PH. Guidance NCSP: programme overview, 2003. Available: https://www.gov.uk/government/publications/ncsp-programmeoverview/ncsp-programme-overview

12 Johansen JR, Dupont M, Obel EB. [Insertion of intrauterine device in general practice. Which women choose the IUD, and how is the procedure done?]. Ugeskr Laeger 2001;163:4574-7.

13 Delen. Delen. Healthcare in the Netherlands. Available: https://www. soaaids.nl/en/information-for/diversity/topics/healthcare-netherlands

14 Thorlby Ruth AS. The English health care system. Available: https:// international.commonwealthfund.org/countries/england/

15 Wammes Joost JP, Gert W, Marit T. The Dutch health care system. Available: https://international.commonwealthfund.org/countries/ netherlands/

16 Karsten V. The Danish healthcare system. Available: https:// international.commonwealthfund.org/countries/denmark/

17 Rawaf S. A proactive general practice: integrating public health into primary care. London J Prim Care 2018;10:17-18.

18 Uusküla A, Ricketts EJ, Rugman C, et al. Provision of Chlamydia testing, and training of primary health care staff about Chlamydia testing, across four European countries. BMC Public Health 2014:14:1147.

19 McNulty C, Ricketts EJ, Fredlund H, et al. Qualitative interviews with healthcare staff in four European countries to inform adaptation of an intervention to increase Chlamydia testing. BMJ Open 2017;7:e017528.

20 Kufeji O, Slack R, Cassell JA, et al. Who is being tested for genital Chlamydia in primary care? Sex Transm Infect 2003;79:234-6.

21 Pimenta JM, Catchpole M, Rogers PA, et al. Opportunistic screening for genital chlamydial infection. I: acceptability of urine testing in primary and secondary healthcare settings. Sex Transm Infect 2003;79:16-21.

22 Strand RHT, Skjeldestad FE, Øvreness T, et al. [Chlamydia trachomatis--pattern of testing and prevalence among young women]. Tidsskr Nor Laegeforen 2004;124:1636-7.

23 McCadden A, Fenton KA, McManus S, et al. Chlamydia trachomatis testing in the second British national survey of sexual attitudes and lifestyles: respondent uptake and treatment outcomes. Sex Transm Dis 2005;32:387-94.

24 Andersen B, Eidner PO, Hagensen D, et al. Opportunistic screening of young men for urogenital Chlamydia trachomatis infection in general practice. Scand J Infect Dis 2005;37:35-9.

25 Harris DI. Implementation of Chlamydia screening in a general practice setting: a 6-month pilot study. J Fam Plann Reprod Health Care 2005;31:109-12.
26 Hughes G, Williams T, Simms I, et al. Use of a primary care database to determine trends in genital Chlamydia testing, diagnostic episodes and management in UK general practice, 1990-2004. Sex Transm Infect 2007:83:310-3.

27 Neale R, Keane F, Saulsbury N, et al. Who attends primary care services prior to attendance at genitourinary services and what level of care have they received? Sex Transm Infect 2008;84:233-4.

28 Sohal $\mathrm{H}$, Creighton S, Figueroa J, et al. The impact of establishing a local-enhanced service for treating sexually transmitted infections in primary care. Sex Transm Infect 2008;84:235-8.

29 Creighton S, Apea V. The evolution of an integrated sexual health service. Int J STD AIDS 2009;20:723-5.

30 Sadler KE, Low N, Mercer $\mathrm{CH}$, et al. Testing for sexually transmitted infections in general practice: cross-sectional study. BMC Public Health 2010;10:667.

31 Woodhall SC, Sile B, Talebi A, et al. Internet testing for Chlamydia trachomatisin England, 2006 to 2010. BMC Public Health 2012;12:1095.

32 Saunders JM, Mercer CH, Sutcliffe LJ, et al. Where do young men want to access STI screening? A stratified random probability sample survey of young men in Great Britain. Sex Transm Infect 2012;88:427-32.

33 Trienekens SCM, van den Broek IVF, Donker GA, et al. Consultations for sexually transmitted infections in the general practice in the Netherlands: an opportunity to improve STI/HIV testing. BMJ Open 2013;3:e003687.

34 van Liere GAFS, Dukers-Muijrers NHTM, van Bergen JEAM, et al. The added value of Chlamydia screening between 2008-2010 in reaching young people in addition to Chlamydia testing in regular care; an observational study. BMC Infect Dis 2014;14.

35 Kelly C, Johnston J, Carey F. Evaluation of a partnership between primary and secondary care providing an accessible level 1 sexual health service in the community. Int J STD AIDS 2014;25:751-7.

36 Pedersen KS, Andersen JS. Social-, age- and gender differences in testing and positive rates for Chlamydia trachomatis urogenital infection - a register-based study. Fam Pract 2014;31:699-705.

37 Buijs SC AW, Boeke AJP, Van Bergen J. Bedroom secrets and urinary tract infections. Huisarts en Wetenschap 2015;58:570-3.

38 Clifton S, Mercer $\mathrm{CH}$, Woodhall SC, et al. Patterns of Chlamydia testing in different settings and implications for wider STI diagnosis and care: a probability sample survey of the British population. Sex Transm Infect 2017:93:276-83.

39 Romoren M, Skaare D, Grude N. Chlamydia testing in practice requisitioners and patients. Tidsskr Nor Laegeforen 2017;137. 